Revista Brasileira de Odontologia Legal - RBOL

\title{
Identificação odontolegal
}

\section{DESASTRES EM MASSA: A UTILIZAÇÃO DO PROTOCOLO DE DVI DA INTERPOL PELA ODONTOLOGIA LEGAL}

\section{Mass Disaster: The use of INTERPOL's Disaster Victims Identification Guide by Forensic Odontology}

Roberto Cesar Biancalana ${ }^{1}$, Maria Gabriela Duarte Morais Vieira ${ }^{1}$, Beatriz Marques de Jesus Figueiredo ${ }^{2}$, Sergio Augusto de Freitas Vicente ${ }^{3}$, Thaís Uenoyama Dezem ${ }^{4}$, Ricardo Henrique Alves da Silva ${ }^{1}$

\footnotetext{
${ }^{1}$ Universidade de São Paulo, Faculdade de Odontologia de Ribeirão Preto, Departamento de Estomatologia, Saúde Coletiva e Odontologia Legal, Área de Odontologia Legal, Brasil.

${ }^{2}$ Polícia Civil do Distrito Federal, Brasil.

${ }^{3}$ Departamento de Materiais Dentários e Prótese. Faculdade de Odontologia de Ribeirão Preto da Universidade de São Paulo, Brasil.

${ }^{4}$ Departamento de Odontologia Social. Faculdade de Odontologia de Piracicaba da UNICAMP, Brasil.
}

Informação sobre o artigo

Recebido: 16 Dez 2015

Aceito em: 06 Jan 2016

\author{
Autor para correspondência \\ Prof. Dr. Ricardo Henrique Alves da Silva \\ Avenida do Café, s/n, Bairro Monte Alegre \\ Ribeirão Preto, São Paulo, Brasil \\ CEP: $14040-904$ \\ Fone: (16) 3315-3969 \\ E-mail: ricardohenrique@usp.br
}

\section{RESUMO}

Desastres em massa são eventos catastróficos e repentinos que requerem uma resposta rápida e eficiente, exigindo para tanto um prévio planejamento por parte dos órgãos responsáveis, principalmente em relação aos familiares das vítimas. Em tais situações, a Odontologia Legal pode se tornar o método de identificação humana mais viável e prático para o estabelecimento da identidade dos corpos. A utilização de um protocolo de condutas mundialmente conhecido se faz importante para que haja uma ação coordenada, organizada, segura, confiável e que facilite a comunicação entre órgãos de diferentes países, mesmo em condições adversas. Nesse contexto, o presente trabalho teve o objetivo de apresentar a utilização do protocolo preconizado pela INTERPOL, por profissionais da área de Odontologia Legal, integrantes das equipes de desastre que atuam na identificação humana das vítimas. Pôde-se concluir que o uso deste protocolo, com responsabilidades definidas, métodos de trabalho pré-estabelecidos e documentos em comum, direciona e orienta os procedimentos desejáveis, agilizando o processo de identificação humana, por profissionais odontolegistas, em casos de grande monta. 


\section{PALAVRAS-CHAVE}

Odontologia Legal, Identificação humana, Equipe de Desastre, Fidelidade a Diretrizes.

\section{INTRODUÇÃO}

Desastre em massa é conceituado como a ocorrência de um evento calamitoso, repentino, instantâneo ou de curta duração, de caráter violento, que, comumente, resulta em dano material significativo, deslocamento considerável de pessoas, elevado número de vítimas, além de notável perturbação da sociedade ${ }^{1}$. A característica peculiar desse tipo de evento é a de ultrapassar a capacidade assistencial, técnica e socorrista do local do incidente, tornando os recursos indisponíveis ou esgotados, sendo, por isso, necessária grande mobilização social e ajuda externa ${ }^{2}$.

Os desastres em massa podem ser resultantes de fenômenos naturais (maremotos, terremotos, alagamentos, tsunamis) ou produzidos pela ação humana, decorrentes da ação ou omissão que resulta em desequilíbrio ambiental, desajuste social ou político ou na redução de padrões de segurança coletivos (quedas de aeronaves, incêndios, explosões, atos terroristas) $)^{3}$.
Nesses incidentes coletivos e catastróficos, o primordial, após o socorro e resgate dos sobreviventes, é a busca pela identidade das vítimas ${ }^{4}$. Existem razões médico-legais, jurídicas e sociológicas, além dos complexos laços afetivos vinculados aos familiares envolvidos, quando se busca a verdadeira identidade dos seres humanos vitimados ${ }^{5}$. No panorama jurídico, tem-se a questão sucessória de bens materiais e, até mesmo, da responsabilidade civil. Em casos de falecimento, por lei, a maioria dos países requer que $\mathrm{o}$ atestado de Óbito seja emitido, não somente para revelar a causa mortis, como também para comprovar civilmente a morte $\mathrm{e}$, consequentemente, solucionar problemas que abranjam: as pensões alimentícias, a guarda de menores, os seguros de vida, a nova situação civil do cônjuge, a preparação do funerário, as aposentadorias, o repasse de dívidas, as heranças e outros benefícios amparados pela Lei Civil ${ }^{6}$. 
A identificação das vítimas nos desastres em massa procede da mesma forma que a realizada em uma identificação individual, ou seja, por meio de comparações. Porém, em tais eventos, as proporções são grandiosas, o que exige maiores cuidados e cautela, principalmente no que se refere à organização, que deve ser rígida e complexa. Todo processo de identificação envolve métodos primários e secundários de identificação humana. Considerados como primários, tem-se a Datiloscopia, o Perfil Genético (ou Perfil de DNA) e a Odontologia Legal $^{7}$.

Dessa maneira, faz-se necessário 0 envolvimento de profissionais especialistas em diversas áreas do conhecimento, inclusive em Odontologia Legal, a fim de compor as equipes periciais, os quais contribuirão na avaliação do local do incidente, nas buscas, recolhimento e separação dos dados post-mortem (PM) e antemortem (AM) de cada vítima, para posterior análise, interpretação e comparação ${ }^{8}$.

Diante da obrigatoriedade da realização de um trabalho criterioso, minucioso, e organizado, ainda mais em condições de extremo cansaço, estresse e pressão psicológica, o presente artigo tem como objetivo apresentar a aplicação do protocolo de identificação de Vítimas de Desastre (Disaster Victim Identification - DVI) ou DVI Guide, preconizado pela INTERPOL, por parte dos profissionais da Odontologia Legal, como guia de orientação ou preparatório de ações a serem seguidos em situações de desastres em massa, no intuito de oferecer uma resposta rápida e eficiente quanto à identificação dos corpos, principalmente aos familiares das vítimas.

\section{PROTOCOLO DE DVI DA INTERPOL (DVI GUIDE)}

A Organização Internacional de Polícia Criminal, conhecida pela sua sigla INTERPOL (International Criminal Police Organization), atua na cooperação da ação policial de diferentes países e criou vários protocolos de investigação e perícia no âmbito criminal, incluindo um protocolo de DVI para servir como modelo em todo o mundo. Dessa forma, oferece aos 190 paísesmembros assistência em incidentes 
de grande monta por meio de uma estrutura de Coordenação e Comando que envia mensagens para todas as Centrais, 24 horas por dia, nos idiomas: árabe, inglês, francês ou espanhol. Além disso, há uma equipe de resposta que fornece auxílio tanto no local de investigação quanto em sua base de dados e um guia (DVI Guide $)^{8}$, disponível em seu site público (http://www.interpol.int).

O DVI Guide fornece diretrizes aos países-membros e tem como objetivo a aplicação de normas de conduta internacionais, incluindo métodos de trabalho e documentos em comum a serem utilizados em operações multinacionais. $\mathrm{O}$ intuito é a sincronização de estratégias diplomáticas, políticas e policiais imediatamente após a ocorrência do desastre, visando uma resposta coordenada, rápida e eficiente ${ }^{8}$.

De acordo com o DVI Guide da INTERPOL, as equipes DVI devem ser interdisciplinares, ou seja, compostas por especialistas das mais diversas áreas do conhecimento como, médicos, odontólogos, psicólogos e policiais. Nos casos da existência de vítimas de mais de um país, deve-se garantir a participação de profissionais de todas as nações envolvidas, a fim de facilitar o intercâmbio de informações, principalmente na obtenção de dados $\mathrm{AM}^{7}$.

Recomenda-se que cada país-membro possua uma ou mais equipes definidas e permanentes, as quais serão responsáveis pela resposta ao evento, além do préplanejamento, preparo e treinamento de pessoal. Se um acidente ocorrer em um país onde não haja uma equipe previamente habilitada e formada, esta deve ser solicitada prontamente à INTERPOL ${ }^{7,9}$.

Ocorrido o desastre, uma equipe (coordenador DVI, médicolegista, odontolegista, policiais) previamente formada deverá chegar ao local e analisar a situação em relação à extensão da área envolvida, ao estado de conservação dos cadáveres, à estimativa da duração do processo, à localização de um Instituto Médico Legal capaz de atender o caso ou, se necessário, avaliar a possibilidade de estabelecimento de um IML de campanha, a uma 
metodologia para remoção dos corpos e à composição e o número de equipes necessárias ao transporte e armazenamento das vítimas $^{7,10,11}$.

Esta equipe, denominada de equipe precursora, realizará uma avaliação do cenário a fim de diagnosticar a situação, com base no número de vítimas, tipo de desastre, sítio da ocorrência, dificuldade de acesso, distância, logística, possíveis locais para transporte dos corpos e realização dos exames necroscópicos, infraestrutura e capacidades locais disponíveis. Ainda deve realizar os primeiros contatos com as autoridades e instituições diretamente envolvidas no desastre e prestar os esclarecimentos sobre a natureza dos trabalhos de identificação e suas necessidades ${ }^{11}$.

Durante o recolhimento dos indícios do local do acidente, profissionais da Odontologia Legal devem atuar devido à presença de remanescentes ósseos do crânio e elementos dentais das vítimas. Partes ou fragmentos de um mesmo corpo devem ser separados e rotulados por meio de placas numeradas, em que cada número deve ser único para cada corpo ou suas partes, inclusive ossos e dentes. A numeração permanece fixada durante todo o processo de identificação e será utilizada para o preenchimento de formulários padronizados pela INTERPOL ${ }^{2,10}$.

\section{FORMULÁRIOS PADRONIZADOS PELA INTERPOL}

Os formulários são divididos em várias seções de dois grupos principais: formulário amarelo (registro dos dados $\mathrm{AM}$ ) e formulário rosa (registro das informações PM). Para a identificação odontológica, utiliza-se a seção "Odontologia", em seus campos de número 600 a 650 no formulário amarelo (AM) e 610 a 650 , no formulário rosa $(\mathrm{PM})^{7}$.

Nos campos 600 a 620 AM (amarelo), devem-se listar todas as informações odontológicas obtidas da vítima quando em vida, indicando as fontes desses registros (Figura 1). Os documentos dos cirurgiões-dentistas devem, preferencialmente, ser originais ou cópias de boa qualidade. Radiografias, modelos de gesso e fotografias necessitam estar devidamente marcados com o nome do paciente, nome do dentista e a 
data da exposição ou produção. Informações adicionais devem ser registradas no campo 620 ou em "Informações Suplementares" que está presente no campo $700^{12}$.

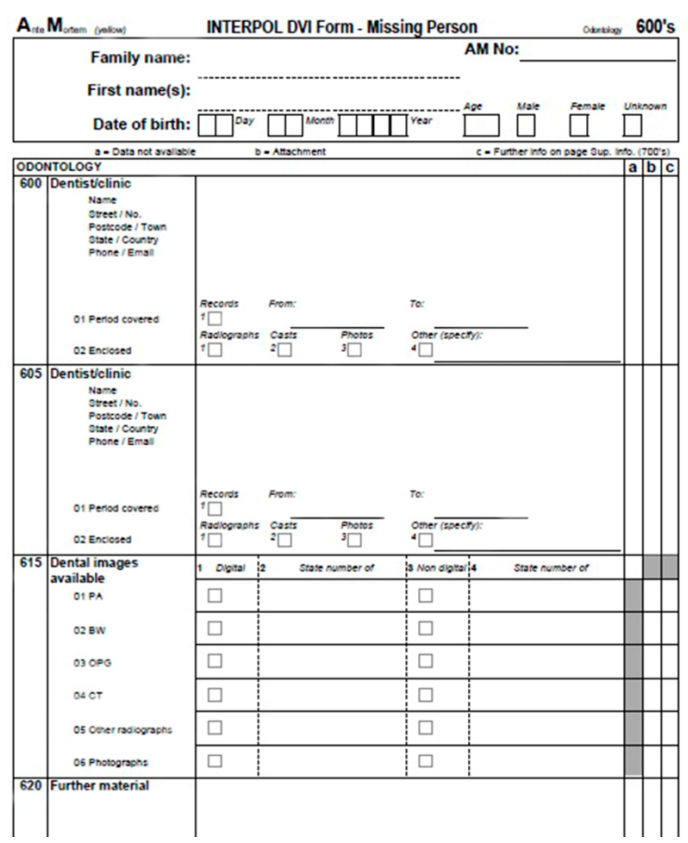

Figura 1. Formulário (AM) - campos 600 a 620 da seção "Odontologia". Fonte: www.interpol.int/INTERPOLexpertise/Forensics/DVI-Pages/Forms.

Nos campos 630 a 650 AM (amarelo) devem ser anotados os últimos registros odontológicos conhecidos da pessoa desaparecida, iniciando pelo material mais recente (Figura 2). Desse modo, todo tratamento realizado anteriormente e coberto ou substituído por outro tratamento posterior será desconsiderado, evitando equívocos. As superfícies dentais devem ser identificadas usando: (M) para mesial; $(\mathrm{O})$ para oclusal; (D) para distal; (V) para vestibular e (L) para lingual. Caso sejam utilizadas outras abreviações, esclarecimentos sobre as mesmas devem ser fornecidos ${ }^{12}$.

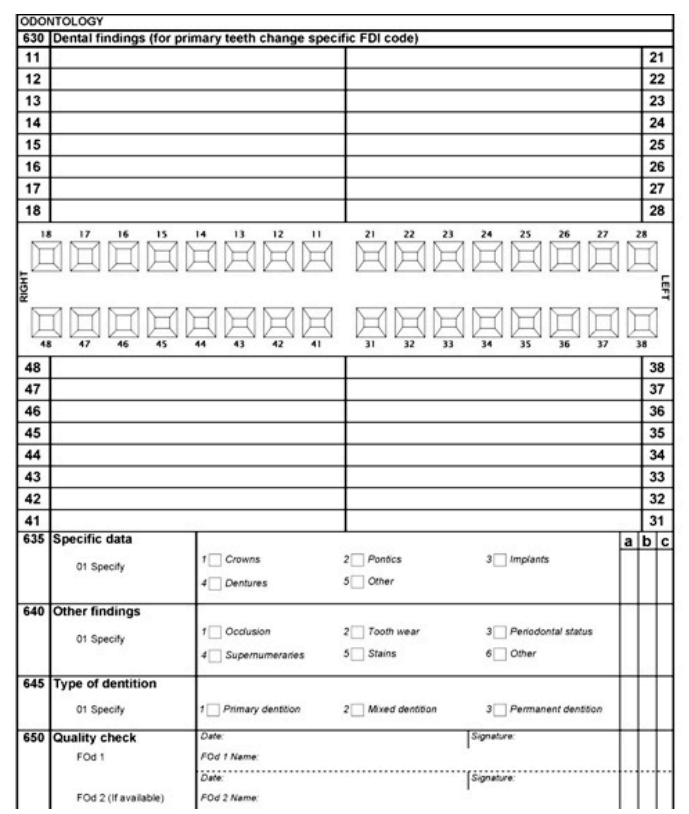

Figura 2. Formulário (AM) - campos 630 a 650 da seção "Odontologia". Fonte: www.interpol.int/INTERPOLexpertise/Forensics/DVI-Pages/Forms.

Nos campos 610 a 625 PM (rosa) devem ser descritos todas as informações coletadas e exames complementares realizados durante o exame necroscópico da cavidade bucal da vítima (Figura 3). Nos campos 630 a 650 PM (rosa) serão inseridos os dados detalhados dos elementos dentais, mantendo a 
mesma nomenclatura do formulário amarelo para identificar as superfícies dos dentes ${ }^{13}$ (Figura 4 ).

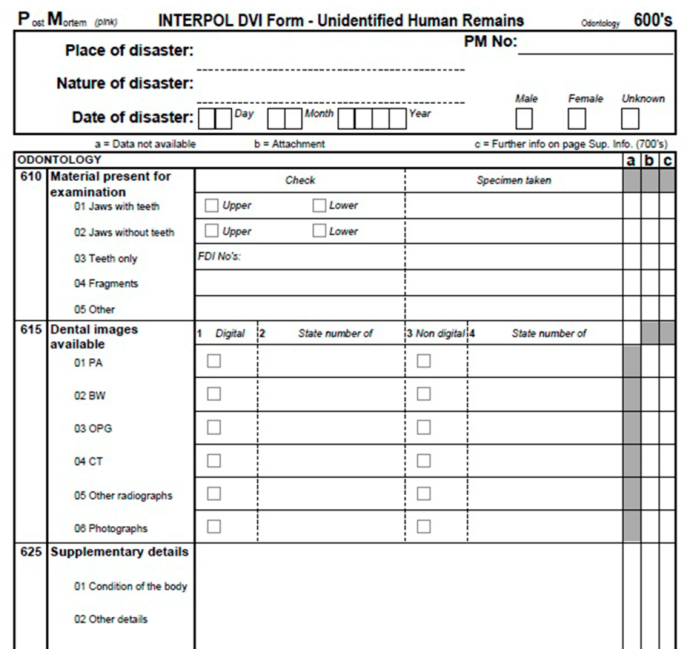

Figura 3 - Formulário (PM) - campos 610 a 625 da seção "Odontologia". Fonte: $\quad$ www.interpol.int/INTERPOLexpertise/Forensics/DVI-Pages/Forms.

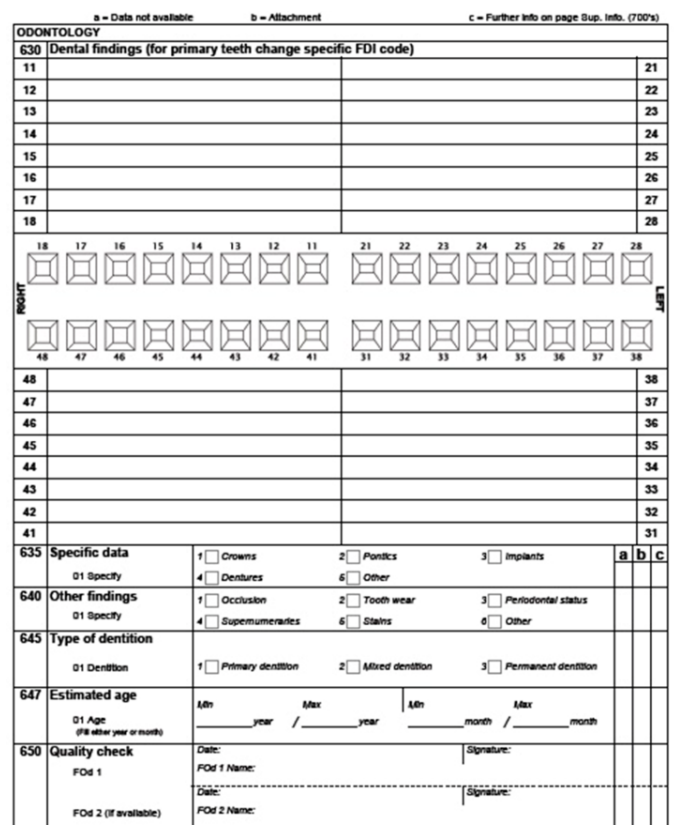

Figura 4 - Formulário (PM) - campos 630 a 650 da seção "Odontologia". Fonte: www.interpol.int/INTERPOLexpertise/Forensics/DVI-Pages/Forms.
Durante o exame PM é necessário um completo acesso à mandíbula e às maxilas, limpeza dos dentes remanescentes e descrição dente a dente (grau de higidez, tratamentos odontológicos e outras condições), tendo início no dente 18 e término no dente 48 . Em seguida, realiza-se o preenchimento do odontograma, com a localização e extensão de todas as restaurações e outras condições encontradas (patologias, ausências dentais, anormalidades $)^{13}$.

Para distinção dos materiais restauradores, preenche-se 0 odontograma em diferentes cores: preto para amálgama, vermelho para ouro e verde para materiais estéticos. Em dentes ausentes no AM, marca-se um "X" sobre o quadrado correspondente; em dentes ausentes no PM, marca-se um "X" envolto por um círculo ${ }^{13}$.

Todas as radiografias devem ser listadas (tipo, data da exposição, dentes envolvidos) e devidamente registradas, assim como outros exames complementares. Finalmente, deve ser feita a estimativa da idade da vítima, informando o método utilizado e o respectivo resultado. Nos 
formulários, indica-se o nome do odontolegista responsável, dados de identificação pessoal (endereço, telefone, carimbo), data e assinatura do profissional. Por se tratar de um documento legal, uma cópia completa deve ser armazenada em arquivo $^{13}$.

\section{IDENTIFICAÇÃO ODONTOLÓGICA}

Em desastres em massa, normalmente, existe a necessidade de identificação de um grande número de indivíduos, os quais podem se encontrar em estado avançado de decomposição, esqueletizados, carbonizados $^{14}$, afogados em que as polpas digitais foram destruídas pela ação da fauna aquática, mutilados, despojados, entre outras condições, nas quais a datiloscopia, provavelmente, será descartada pela impossibilidade da obtenção de registros no $\operatorname{corpo}^{15}$. Há a possibilidade, também, da utilização do exame de DNA, mas, por ser um método oneroso para a aplicação e pelo fato de pessoal tecnicamente preparado não estar disponível em todas as localidades, por tantas vezes é descartado ${ }^{16}$, ou deixado como última opção.
Além disso, os dentes são formados pelos tecidos mais resistentes do corpo humano especialmente à ação do tempo, temperatura e umidade ${ }^{17}$. Por estas características e após a ocorrência de um desastre em massa, independente das condições climáticas ou geográficas do local do incidente, provavelmente ainda se farão presentes e em condições de higidez passível de análise. Esses fatores, portanto, são capazes de tornar a Odontologia Legal o método de escolha mais viável em determinadas ocasiões de desastres em massa ${ }^{18}$.

O método odontológico é um processo baseado em fundamentos científicos sobre a análise especializada dos arcos dentais e dentição humana, o qual preenche todos os requisitos biológicos (unicidade, imutabilidade e perenidade) e técnicos (praticabilidade, reprodutibilidade e classificabilidade) de um processo de identificação humana aplicável ${ }^{19}$.

A identificação odontológica é um método comparativo, por isso durante o exame do crânio e seus respectivos arcos dentais, é crucial a presença de dados odontológicos 
(radiografias, tomografias, fotografias do sorriso ${ }^{20,21}$, modelos de gesso, placas de clareamento, próteses bucais, fichas clínicas) fornecidos pelos cirurgiões-dentistas que atendiam a vítima quando em vida, no intuito de possibilitar a análise comparativa. Dessa maneira, os familiares das vítimas têm participação fundamental para obtenção dos registros $\mathrm{AM}^{17}$.

O processo de identificação pela Odontologia Legal deve ser subdividido em três subprocessos que serão efetuados por três equipes distintas: a) Equipe postmortem (PM) - busca, coleta e documentação de informações por meio de exame dos corpos e descrição detalhada do crânio e cavidade bucal, realizada por odontolegistas da equipe PM; b) Equipe ante-mortem (AM) - busca, coleta e uniformização de dados odontológicos das vítimas quando em vida, junto aos familiares, o qual servirá para o confronto com os dados PM, realizada pelos odontolegistas da equipe $\mathrm{AM} ; \mathrm{c}$ ) Equipes de confronto - avaliação e combinação das informações AM e $\mathrm{PM}^{7,8,11,22}$, realizada por odontolegistas da equipe de comparação.

A identificação positiva ou exclusão de um indivíduo somente será possível se os dados presentes no formulário rosa puderem ser comparados com os dados listados no formulário amarelo. Nos casos de identificação positiva, os odontolegistas envolvidos preencherão 0 documento "Identification-Report", que serve como pré-requisito para a emissão do atestado de Óbito e liberação do corpo para o sepultamento ${ }^{7}$.

\section{DISCUSSÃO}

O processo completo e preciso de identificação dos corpos e das evidências deve ser iniciado no próprio local do acidente. A presença do odontolegista, como integrante das equipes de desastre, visa à coleta do maior número possível de elementos do complexo bucomaxilofacial dos corpos e que podem ser cruciais na identificação de cada indivíduo ${ }^{23}$.

O número de equipes que atuarão diretamente na identificação será determinado em razão da disponibilidade de pessoal e 
dimensão do desastre, sendo proporcional ao número estimado de vítimas. É recomendado que o número mínimo de cirurgiõesdentistas seja na relação de dois para cada 30 vítimas fatais ${ }^{24}$.

Para a Odontologia, a maior dificuldade encontra-se na obtenção das informações AM, principalmente quando se tratam de vítimas provenientes de diferentes países. A quantidade e a qualidade dos registros dentais AM são fundamentais para adequada comparação com os achados PM. A dificuldade da obtenção de registros adequados pode ser considerada a maior desvantagem do método odontológico frente a tantas outras qualidades, como a individualidade e o baixo custo ${ }^{25}$.

Erros de preenchimento de fichas clínicas, falta de anotações ou anotações errôneas podem conduzir a impossibilidades de identificação. Evidencia-se, assim, a importância da guarda e arquivamento do prontuário odontológico com dados atualizados dos pacientes pelos cirurgiõesdentistas, por período de tempo indeterminado, visto sua importância, não somente para o acompanhamento clínico, como também para a identificação humana ${ }^{25}$.

Dessa forma, a taxa de sucesso da identificação pelos achados odontológicos pode variar consideravelmente, na dependência da natureza do acidente, da nacionalidade e do país de residência das vítimas, da incidência de tratamentos dentais, da disponibilidade de registros e do grau de lesões traumáticas envolvendo as peças dentais ${ }^{24}$. Além de comparar registros $\mathrm{AM}$ e $\mathrm{PM}$, a Odontologia pode oferecer informações que delimitam o critério de pesquisa na base de dados, como aspectos, estilos de vida ou profissão de determinada pessoa, estimativa de idade pelo desenvolvimento dos dentes, doenças congênitas e/ou adquiridas ${ }^{7}$.

Preferencialmente, a equipe PM deve ser composta por, no mínimo, três cirurgiões-dentistas, em que um deles realiza o exame detalhado da cavidade bucal do cadáver; o segundo profissional registra todos os achados odontológicos do exame PM em ficha específica, já revisando as 
informações obtidas, a fim de garantir sua qualidade; e o terceiro cirurgião-dentista encarrega-se da realização dos exames radiográficos dos elementos dentais, quando necessário. A equipe de comparação deve ser composta, idealmente, por odontolegistas não participantes das equipes $\mathrm{AM}$ ou PM, no intuito de evitar que o prévio conhecimento dos dados contamine a análise imparcial desta etapa ${ }^{26}$.

A utilização de um protocolo pré-estabelecido de atuação está diretamente relacionado ao melhor preparo da equipe para $\mathrm{O}$ recolhimento de dados AM junto aos familiares das vítimas. Equívocos por falta de preparo nas investigações das informações odontológicas certamente causarão atrasos ou erros na ação, além de maior sofrimento e ansiedade dos familiares, tanto pela demora na identificação como pela provável necessidade de interrogatórios posteriores $^{24}$.

Devido à intensa carga emocional envolvida nesses eventos, o uso de um protocolo pode facilitar a organização e coordenação dos atos (coleta de material, transporte, guarda) das equipes de $\mathrm{DVI}$, a comunicação entre as mesmas, pelo uso de nomenclaturas padronizadas, $\mathrm{O}$ relacionamento com as famílias, imprensa e autoridades, o entendimento das informações por todos os países-membros, enfim, todo o processo de identificação humana ${ }^{7,27}$.

Entretanto, existem autores ${ }^{28-}$ ${ }^{30}$ que consideram o protocolo como algo que restringe a atuação da equipe, já que cada evento é único, exigindo dessa maneira, diferentes planejamentos, condutas e respostas devido às particularidades de cada local. Por outro lado, em situações como o tsunami da Ásia (2004), o acidente do voo 447 da Air France (2009) e o terremoto, seguido de tsunami, no Japão (2011), nas quais se deram o uso do protocolo da INTERPOL, os resultados das ações mostraram-se bastante satisfatórios ${ }^{31}$.

Apesar de cada evento ou situação crítica distinguir-se uma da outra, a necessidade de uma intervenção especial dos órgãos responsáveis, objetivando abordálos, entendê-los, de certa forma preveni-los, em acidentes evitáveis, e de buscarem soluções aceitáveis, 
éticas, organizadas e coordenadas, requer a existência de um protocolo de ações e estratégias a serem seguidas. Ações pré-definidas proporcionam melhor planejamento na formação e preparo das equipes atuantes em desastres em massa, no atendimento aos familiares, na aplicação dos recursos financeiros e humanos e nos métodos de cooperação internacional ${ }^{11}$.

O uso do protocolo é essencial para direcionar as condutas que devem ser realizadas pelas equipes de desastre. Porém, somente a utilização de documentos padronizados não é suficiente para uma resposta adequada frente a uma situação de crise. Existe a necessidade de uma infraestrutura de apoio (limpeza, alimentação, acomodação, transporte, materiais descartáveis, caixões, caminhões frigoríficos, serviços de telefonia e informática), incentivo de programas de treinamentos teórico-práticos, ensaios de estratégias que permitam uma simulação da realidade, controle do número de horas trabalhadas por dia e por semana com intervalos de descanso, além de assistência psicológica, tudo a fim de melhor preparar os profissionais da Odontologia para atuarem nas atividades de identificação dentro de um padrão de qualidade aceitável.

\section{CONSIDERAÇÕES FINAIS}

Um protocolo de identificação odontolegal deve ser minucioso e de interpretação mundial, além de apresentar aplicabilidade, baixo custo e eficácia, ainda que em condições adversas. O DVI Guide da INTERPOL abrange tais aspectos e mostra-se satisfatório em situações reais de catástrofes. Portanto, sua utilização pela Odontologia Legal é altamente eficiente e recomendável para a identificação humana em casos de desastres em massa.

\section{ABSTRACT}

Mass disasters are catastrophic and sudden events that require a previously planned, quickly and efficiently management by the responsible institutions, especially with regard to victim's families. In these situations, forensic odontology can become the more viable and practical human identification method to establish the identity of the dead bodies. The use of a worldwide known protocol is important for a coordinated action, organized, safe, reliable, and also 
facilitates the communication between the different countries agencies, even in adverse conditions. In this context, the aim of this study was to present and discuss the use of the DVI Guide proposed by INTERPOL for forensic odontologists - members of the disaster teams working in victim's human identification. It was concluded that the use of this DVI Guide, and its defined responsibilities, pre-established working methods and documents in common, directs and guides the wanted procedures, streamlining the human identification process, by forensic odontologists, in mass casualty incidents.

\section{KEYWORDS}

Forensic Dentistry. Forensic Anthropology, Disaster Team, Guideline Adherence Charges.

\section{REFERÊNCIAS}

1. Organização das Nações Unidas (ONU). Década Internacional de Redução de Riscos de Desastres Naturais (1990-1999) - DIRDN. Resolução n. 44/236, de 22 de dezembro de 1989.

2. Stavrianos C, Kokkas A, Andreopoulos

E, Eliades A. Applications of forensic dentistry: part I. Res J Med Sci. 2010; 4(3): 179-86.

3. Skinner M, Sterenberg J. Turf wars: Authority and responsibility for the investigation of mass graves. Forensic Sci Int. 2005; 151(2-3): 221-32. DOI: http://dx.doi.org/10.1016/j.forsciint.2004.12. 034.

4. Allen-Hall A, McNevin D. Human tissue preservation for disaster victim identification (DVI) in tropical climates. Forensic Sci Int: Genetics. 2012; 6(5): 653-7. DOI: http://dx.doi.org/10.1016/j.fsigen.2011.12.0 05.

5. Gruber J, Kameyama MM. O papel da Radiologia em Odontologia Legal. Pesq Odontol Bras. 2001; 15(3): 263-8.

6. França GV. Medicina Legal. 10 ed. Rio de Janeiro: Guanabara Koogan; 2015.
7. Interpol. Disaster Victim Identification Guide (Proposed Amendments: March, 2014), (2014). Disponível em URL: www.interpol.int/INTERPOLexpertise/Forensics/DVI-pages/DVI-guide.

8. Sweet D. INTERPOL DVI best-practice standards - an overview. Forensic Sci Int. 2010; 201(1): 18-21. DOI: http://dx.doi.org/10.1016/j.forsciint.2010.02. 031.

9. Funabashi KS, Monteiro AC, de Moraes DA, Rocha MR, Moreira PCF, Iwamura ESM. A importância da identificação humana nos desastres de massa naturais, acidentais ou provocados: uma abordagem multidisciplinar. Saúde, Ética \& Justiça. 2009; 14(2): 54-64. DOI: http://dx.doi.org/10.11606/issn.2317-

2770.v14i2p.

10. Byard RW, Winskog C. Potential problems arising during international disaster victim identification (DVI) exercises. Forensic Sci Med Pathol. 2010; 6(1): $1-2 . \quad$ DOI: http://dx.doi.org/10.1007/s12024-009-91415. 
11. Brasil. Ministério da Justiça. Manual de Procedimentos em Odontologia para Identificação de Vítimas de Desastre. Departamento de Polícia Federal e Secretaria Extraordinária de Segurança para Grandes Eventos. Brasília; 2014.

12. Interpol. AM-DVI-Form. Disponível em URL: $\quad$ http://www.interpol.int/INTERPOLexpertise/Forensics/DVI-Pages/Forms.

13. Interpol. PM-DVI-Form. Disponível em URL: $\quad$ http://www.interpol.int/INTERPOLexpertise/Forensics/DVI-Pages/Forms.

14. Bittencourt EAA, Koshikene D, de Freitas Junior DT, da Cunha LKH, dos Santos Neves M, Pacheco AC, et al. Disaster carbonized victims identification in State of Rondonia, Brazil. Forensic Sci Int: Genetics Supplement Series. 2009; 2(1): 248-9.

DOI: http://dx.doi.org/10.1016/j.fsigss.2009.08.14 3.

15. Senn DR, Stimson PG. Forensic Dentistry. 2 ed. New York: CRC Press Taylor \& Francis; 2010.

16. Michaud CL, Foran DR. Simplified Field Preservation of Tissues for Subsequent DNA Analyses. J Forensic Sci. 2011; 56(4): 846-52.

DOI: http://dx.doi.org/10.1111/j.1556-

4029.2011.01771.x.

17. Woisetschläger $M$, Lussi A, Persson A, Jackowski $C$. Fire victim identification by post-mortem dental $\mathrm{CT}$ : radiologic evaluation of restorative materials after exposure to high temperatures. Eur J Radiol. 2011; 80(2): 432-40. DOI: http://10.1016/j.ejrad.2010.06.012.
18. Fereira JL, de Fereira AE, Ortega Al. Methods for the analysis of hard dental tissues exposed to high temperatures. Forensic Sci Int. 2008; 178(2-3): 119-24. DOI:

http://dx.doi.org/10.1016/j.forsciint.2007.12. 009.

19. Rothwell BR. Principles of dental identification. Dent Clin North Am. 2001; 45(2): 253-70.

20. Terada A, Leite NLP, Silveira TCP, Secchieri JM, Guimarães MA, Silva RHA. Identificação humana em odontologia legal por meio de registro fotográfico de sorriso: relato de caso. Rev Odontol UNESP. 2011; 40(4): 199-202.

21. Silva RF, Lima LNC, Martorell LB, Prado MM, Francesquini Júnior L, Daruge Júnior E. Comparative study among Dentistry undergraduates and Forensic Odontology postgraduate students through smile photographs for human identification RSBO. 2012; 9(4): 407-15.

22. Valck E. Major incident response: collecting ante-mortem data. Forensic Sci Int. 2006; 159(1): S15-S9. DOI: http://dx.doi.org/10.1016/j.forsciint.2006.02. 004.

23. Berketa JW, James $H$, Lake AW. Forensic odontology involvement in disaster victim identification. Forensic Sci Med Pathol. 2012; 8(2): 148-56. DOI: http://dx.doi.org/10.1007/s12024-011-92799. 
24. Schou MP, Knudsen PJT. The Danish Disaster Victim Identification effort in the Thai tsunami: organization and results. Forensic Sci Med Pathol. 2012; 8(2): 12530. DOI: http://dx.doi.org/10.1007/s12024011-9297-7.

25. Araujo LG, Biancalana RC, Terada ASSD, Paranhos LR, Machado CEP, Silva RHA. A identificação humana de vítimas de desastres em massa: a importância e o papel da Odontologia Legal. RFO. 2013; 18(2): 224-9.

26. Solheim $T$, Lorentsen $M$, Sundnes PK, Bang G, Bremnes L. The "Scandinavian Star" ferry disaster 1990 - a challenge to forensic odontology. Int J Legal Med. 1992; 104(6): 339-45.

DOI: http://dx.doi.org/10.1007/BF01369554.

27. Hill AJ, Hewson I, Lain R. The role of the forensic odontologist in disaster victim identification: Lessons for management. Forensic Sci Int. 2011; 205(1): 44-7. DOI: http://dx.doi.org/10.1016/j.forsciint.2010.08. 013.

28. Lake A, James H, Berketa J. Disaster victim identification: quality management from an odontology perspective. Forensic Sci Med Pathol. 2012; 8(2): 157-63. DOI: http://dx.doi.org/10.1007/s12024-011-9286$\mathrm{x}$.

29. Shekar CBR, Reddy CVK. Role of dentist in person identification. Indian $\mathrm{J}$ Dent Res. 2009; 20(3): 356-60. DOI: http://dx.doi.org/10.4103/0970-9290.57377. 30. Blau S, Briggs CA. The role of forensic anthropology in Disaster Victim Identification (DVI). Forensic Sci Int. 2011; 205(1): 29-35. DOI: http://dx.doi.org/10.1016/j.forsciint.2010.07. 038.

31. Polícia Civil Do Distrito Federal. Plano de Contingência para atuação em eventos fatais com multidão. Departamento de Polícia Técnica. Brasília; 2008. 